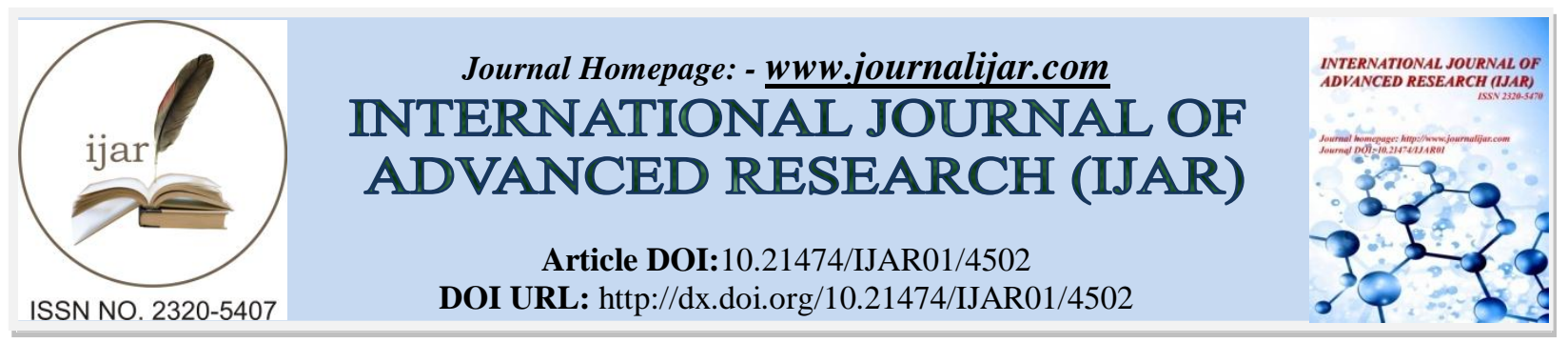

RESEARCH ARTICLE

\title{
CONCURRENT WHOLE BRAIN IRRADIATION WITH OR WITHOUT TEMOZOLOMIDE IN TREATMENT OF BRAIN METASTASES FROM BREAST CANCER.
}

Mohamed abdelgawad MD, Eman IsmailMD and Abbas SarhanMD.

Clinical Oncology Department, Faculty Of Medicine, ZagazigUniversity ,Egypt.

\section{Manuscript Info}

Manuscript History

Received: 16 April 2017

Final Accepted: 18 May 2017

Published: June 2017

\section{Abstract}

Background : to evaluate the response rate, survival and safety of the combination of temozolamide and whole brain radiotherapy in breast cancer patients with previously untreated brain metastases

Patients and Methods: 40 patients with brain metastases were divided in two groups Control $\operatorname{arm}(\mathrm{A})$ : patients received whole brain radiotherapy(WBRT) at a dose of $30 \mathrm{~Gy}$ in 10 daily fractions over 2 weeks. TMZ plus WBI arm (B): patients treated with (WBRT) at a dose of 30 Gy in 10 daily fractions over 2 weeks concomitant with temozolamide.

The primary endpoint was overall response (OR) Secondary endpoints were progression free survival (PFS) and overall survival (OS)

Results: Patients who received WBI and TMZ had an overall response of $45 \%$ compared with $40 \%$ in WBI alone with no statistically significant difference. Brain metastasis progression was observed in $45 \%$ in the control group(A) versus $15 \%$ in group B with a statistically significant difference $(\mathrm{p}=0.038)$.

Median progression free survival ( PFS) was 6 months in group A but 9.5 in group B with non significant difference. One year progression free survival was $37.5 \%$ in group A versus $45 \%$ in group B . One year overall survival was $33.3 \%$ in group A versus $47.8 \%$ in group B .

Median overall survival was 7 months in group A versus 11 months in group B with non-significant difference.

Most of patients had tolerable side effects and recovered eventually.

Conclusion: Although, the combination of WBRT and TMZ was safe and appeared to improve local control, OS and PFS of BMs from breast cancer in this study, this improvement was non- significant, and further studies with larger number of patients are needed to get significant results.

Copy Right, IJAR, 2017,. All rights reserved.

\section{Introduction:-}

Brain metastasesare considered important cause of mortality and morbidity in cancer patients, and in adult patients with cancer, they constituted the most common brain tumor, occurring in approximately $10 \%$ to $30 \%$ of cases(1).

In breast cancer, depending on the molecular subtype, BM incidence varies from 5\% to $30 \%$ in patients with metastatic breast cancer (2). 
Brain metastases incidence has increased in recent years, and they are associated with poor prognosis. Brain metastases patients suffer from decrease in survival,worse quality of life and severe neurologic symptoms (3).

Patients with brain metastases have standard systemic therapy. Radiotherapy whole-brain remains the standard of care in patients with multiple brain metastases but with limited efficacy, with less than six months median overall survival (4). Nevertheless, radiosurgery may be indicated as an option for young patients with up to four lesions, with good performance status and controlled other extracranial metastases (5).

The role chemotherapy was limited and used as salvage therapy in patients who did not give a response to whole brain radiation or radiosurgery. However, the supposition that the blood-brain barrier(BBB)doesn't allow the passage of chemotherapeutic agents through the brain;limit the use of chemotherapy in the treatment of brain metastases, despite BBB might already be distorted by the presence of brain metastases and the radiation effectof whole-brain radiotherapy(6).

Temozolomide (TMZ) is an oral alkylating agent with a good safety profile that can pass through the blood-brain barrier. Presently,TMZ is a primary therapy in treatment of high grade gliomas. Synergetic effects of radiotherapy and TMZ have been reported in vitro and in vivo. Various phase II trials have shown promising response rates using concurrent TMZ and whole brain irradiation (WBI) in cases of brain metastasis, with a good impact of this combination on quality of life (7).

\section{Aim of the study:-}

The aim of current studywas to evaluate the response rate,survival and safety of concurrent temozolomide and WBI in previously untreated brain metastases of breast cancer patients.

\section{Patients and Methods:-}

This study was prospectively conducted on 40 patients with brain metastases from breast cancer presented to Clinical Oncology Department at Zagazig University Hospitals from May 2013 to January 2016. .Patients were divided into two groups ; group A included 20 patients ( control group) and group B included 20 patients ( study group)

\section{Inclusion Criteria:-}

Age: 18 to 80 years, with performance status(Karnofsky scale KPS) $\geq 50 \%$, histologically confirmed breast cancer as primary site, extra cranial metastases or an uncontrolled primary tumor are allowed, life expectancy $\geq 3$ months and normal hematological profile.

\section{Exclusion Criteria:-}

systemic chemotherapy within the last 3 weeks, prior surgery, chemotherapy or radiotherapy for a brain neoplasm and severe medical illness.

Study plan: Patients in this study were randomly divided into two groups; Control arm(A): patients received whole brain radiotherapy(WBRT) at a dose of $30 \mathrm{~Gy}$ in 10 daily fractions over 2 weeks. TMZ plus WBI arm (B): patients treated with (WBRT) at a dose of $30 \mathrm{~Gy}$ in 10 daily fractions over 2 weeks concomitant with temozolamide.

Pretreatment evaluation of the patients included clinical evaluation in the form of medical history and complete physical and neurological examination and radiological examination with contrast enhanced computed tomography (CT) scan or gadolinium- enhanced magnetic resonance imaging (MRI) for assessment and measurement of brain metastases.

Patients received WBRT to a dose of $30 \mathrm{~Gy}$ in ten fractions given 5 days a week. WBRT was applied with two parallel and opposing fields using Cobalt 60 or $6 \mathrm{MV}$ photon beam .

In the WBRT + TMZ arm, TMZ was administered $1 \mathrm{~h}$ before each WBI fraction, with the patients having fasted for $1 \mathrm{~h}$, at a dose of $200 \mathrm{mg}$ on (D1,3,5,8,10,12) and at a dose of $300 \mathrm{mg}$ on $(\mathrm{D} 2,4,9,11)$.

No additional doses of TMZ were administered. Antiepileptic and corticosteroids drugs were administered at the lowest dosage, when necessary. 
Assessment of endpoints and follow up: The first follow-up visit was 2 weeks after completion of the protocol treatment and monthly thereafter until loss of follow up or death of the patient. Each visit included clinical and neurological evaluation, and laboratory evaluation. Brain MRI was done every 2 months for evaluation of response.

Radiologic response of target lesions was performed according to WHO criteria. The primary endpoint was overall response (OR) .Secondary endpoints were progression free survival (PFS) and overall survival ( OS),PFS is measured from the date of diagnosis of BM to the date of progression and OS is measured from the date of diagnosis of BM to the date of death resulting from any cause. Systemic side effects and adverse events were evaluated according to Common Terminology Criteria for Adverse Events (CTCAE)Version 4.0.

\section{Statistical Analysis:-}

All data were analyzed using SPSS 18.0 for windows (SPSS Inc., Chicago, IL, USA) \&MedCalc 13 for windows (MedCalc Software bvba, Ostend, Belgium). $\mathrm{p}<0.0$ was considered statistically significant $(S), p<0.01$ was considered highly statistically significant (HS), and $\mathrm{p} \geq 0.05$ was considered non statistically significant NS.

\section{Results:-}

Between May 2013 and January 2016, 40 patients were entered the study .Demographic and tumor characteristics of patients in the study groups did not differ significantly as regard age, KPS, prior chemotherapy ,extra cranial metastasis, symptoms and number of metastasis (table 1).

\section{Response to treatment:-}

Patients who received WBI and TMZ had an overall response of $45 \%$ compared with $40 \%$ in WBI arm with no statistically significant difference. Actually no CR was obtained and all responses in both group were partial (table 2).

Univariate analysis showed no significant difference in response regarding number of brain metastasis ,age, KPS, prior chemotherapy and presence or absence of extra cranial metastasis ( table 3 ).

Follow up of 12 months showed that brain metastasis progression was observed in (45\%) in control group(A) versus $(15 \%)$ in group B with statistically significant difference $(\mathrm{p}=0.038)$ (table 2$)$.

The univariate analysis of the brain metastasis progression showed non-significant difference regards to number of metastasis, age, KPS,prior chemotherapy and presence or absence of extra cranial metastasis (table 4). Also the univariate analysis of the brain metastasis progression and response to treatment were non-significant difference.

\section{Survival:-}

Median progression free survival ( PFS) was 6 months in group A but 9.5 in group B with non significant difference $(\mathrm{p}=0.197)$. One year progression free survival was $37.5 \%$ in group A versus $45 \%$ in group B (figure 1 ).

Median overall survival was 7 months in group A versus 11 months in group B with non-significant difference $(\mathrm{p}=0.143)$. One year overall survival was $33.3 \%$ in group A versus $47.8 \%$ in group B (figure 2 ).

The analysis of survival according to the presens or abscens of response showed significant difference (pvalue $<0.001$ )(figure 3 ), also this analysis showed that survival significally affected by presence of brain metastasis progression difference ( $\mathrm{p}$-value $=0.014$ ) (figure 4).

\section{Treatment toxicity:-}

Most patients had tolerable side effects and recovered eventually.Leucopenia was the most frequent observed hematologic toxicity $(30 \%)$ in group A versus $(50 \%)$ in group. In non-hematologic toxicities headache was the most frequent ; $(75 \%)$ in group A versus (55\%) in group B. Most side effects were grade 2 and were controlled by supportive care as shown in table (5) 
Table 1:- Patient characteristics.

\begin{tabular}{|c|c|c|c|c|c|}
\hline \multirow[t]{2}{*}{ Patient characteristics } & \multicolumn{2}{|c|}{$\begin{array}{c}\text { (WBI )A } \\
\text { (20) }\end{array}$} & \multicolumn{2}{|c|}{$\begin{array}{c}(\mathrm{WBI}+\mathrm{TMZ}) \mathrm{B} \\
(20)\end{array}$} & \multirow[t]{2}{*}{ p-value (Sig.) } \\
\hline & No. & $\%$ & No. & $\%$ & \\
\hline \multicolumn{6}{|l|}{ Age (years) } \\
\hline Mean \pm SD & \multicolumn{2}{|c|}{$47.9 \pm 12.2$} & \multicolumn{2}{|c|}{$48.7 \pm 10.8$} & $0.828(\mathrm{NS})$ \\
\hline$<65$ years & 16 & $80 \%$ & 15 & $75 \%$ & $0.705(\mathrm{NS})$ \\
\hline$\geq 65$ years & 4 & $20 \%$ & 5 & $25 \%$ & \\
\hline KPS (\%) & & & & & \\
\hline$<70 \%$ & 3 & $15 \%$ & 2 & $10 \%$ & $0.500(\mathrm{NS})$ \\
\hline$\geq 70 \%$ & 17 & $85 \%$ & 18 & $90 \%$ & \\
\hline
\end{tabular}

\begin{tabular}{|c|c|c|c|c|c|}
\hline \multicolumn{6}{|l|}{ Number of metastasis } \\
\hline$\leq 4$ & 13 & $65 \%$ & 15 & $75 \%$ & $0.366(\mathrm{NS})$ \\
\hline$>4$ & 7 & $35 \%$ & 5 & $25 \%$ & \\
\hline \multicolumn{6}{|l|}{ Prior chemotherapy } \\
\hline Absent & 2 & $10 \%$ & 4 & $20 \%$ & $0.661(\mathrm{NS})$ \\
\hline Present & 18 & $90 \%$ & 16 & $80 \%$ & \\
\hline \multicolumn{6}{|l|}{ Extracranial metastasis } \\
\hline Absent & 10 & $37.9 \%$ & 7 & $35 \%$ & $0.337(\mathrm{NS})$ \\
\hline Present & 10 & $62.1 \%$ & 13 & $65 \%$ & \\
\hline \multicolumn{6}{|l|}{ Symptoms\& signs } \\
\hline Headache & 16 & $80 \%$ & 17 & $85 \%$ & $0.487(\mathrm{NS})$ \\
\hline Seizures & 4 & $24.1 \%$ & 2 & $34.5 \%$ & $0.661(\mathrm{NS})$ \\
\hline Neurological deficit & 15 & $51.7 \%$ & 12 & $41.4 \%$ & $0.525(\mathrm{NS})$ \\
\hline Cognitive dysfunction & 8 & $27.6 \%$ & 10 & $34.5 \%$ & $0.311(\mathrm{NS})$ \\
\hline Gait change & 10 & $34.5 \%$ & 11 & $37.9 \%$ & $0.490(\mathrm{NS})$ \\
\hline
\end{tabular}

Table 2:- Response to treatment and events.

\begin{tabular}{|c|c|c|c|c|c|}
\hline & \multicolumn{2}{|c|}{$\begin{array}{c}\text { (WBI )A } \\
\text { (20) }\end{array}$} & \multicolumn{2}{|c|}{$\begin{array}{c}\text { (WBI+TMZ) B } \\
(20)\end{array}$} & \multirow[t]{2}{*}{ p-value } \\
\hline & No. & $\%$ & No. & $\%$ & \\
\hline \multicolumn{6}{|l|}{ Response to treatment: } \\
\hline Overall Response & 8 & $40 \%$ & 9 & $45 \%$ & \multirow[t]{2}{*}{$0.749(\mathrm{NS})$} \\
\hline No response & 12 & $60 \%$ & 11 & $55 \%$ & \\
\hline \multicolumn{6}{|c|}{ Brain metastasis is progression : } \\
\hline Not progressed & 11 & $55 \%$ & 17 & $85 \%$ & \multirow[t]{2}{*}{$0.038(\mathrm{~S})$} \\
\hline Progressed & 9 & $45 \%$ & 3 & $15 \%$ & \\
\hline
\end{tabular}

Table 3:- Relation between response to WBI+TMZ and basic characteristics.

\begin{tabular}{|c|c|c|c|c|c|}
\hline \multirow{2}{*}{ Basic characteristics } & \multicolumn{2}{|c|}{ Response $(\mathrm{N}=9)$} & \multicolumn{2}{c|}{ No Response(N=11) } & \multirow{2}{*}{ p-value (Sig.) } \\
\cline { 2 - 5 } & No. & $\%$ & No. & $\%$ & \\
\hline Age (years) & & & & & \multirow{2}{*}{0.436 (NS) } \\
\hline$<65$ years & 6 & $66.7 \%$ & 9 & $81.8 \%$ & \\
\hline$\geq 65$ years & 3 & $33.3 \%$ & 2 & $18.2 \%$ & \\
\hline KPS $(\%)$ & & & & & $0.711(\mathrm{NS})$ \\
\hline$<70 \%$ & 1 & $11.1 \%$ & 1 & $9.1 \%$ & \\
\hline$\geq 70 \%$ & 8 & $88.9 \%$ & 10 & $90.9 \%$ & \multirow{2}{*}{0.194 (NS) } \\
\hline Number of metastasis & & & & & \\
\hline$\leq 4$ & 8 & $88.9 \%$ & 7 & $63.6 \%$ & \multirow{2}{*}{0.625 (NS) } \\
\hline$>4$ & 1 & $11.1 \%$ & 4 & & \\
\hline Prior chemotherapy & & & & & \\
\hline Absent & 2 & $22.2 \%$ & 2 & $18.2 \%$ & \\
\hline
\end{tabular}




\begin{tabular}{|c|c|c|c|c|c|}
\hline Present & 7 & $77.8 \%$ & 9 & $81.8 \%$ & \\
\hline Extracranial metastasis & & & & & \\
\hline Absent & 4 & $44.4 \%$ & 3 & $27.3 \%$ & 0.370 (NS) \\
\hline Present & 5 & $55.6 \%$ & 8 & $72.7 \%$ & \\
\hline
\end{tabular}

Table 4:-Univariate analysis for relation between brain metastasis progression and basic characteristics and response.

\begin{tabular}{|c|c|c|c|c|c|}
\hline \multirow[t]{3}{*}{ Basic characteristics } & \multicolumn{4}{|c|}{ Brain metastasis progression } & \multirow[t]{3}{*}{ p-value (Sig.) } \\
\hline & \multicolumn{2}{|c|}{ Absent $(\mathrm{N}=17)$} & \multicolumn{2}{|c|}{ Present $(\mathrm{N}=3)$} & \\
\hline & No. & $\%$ & No. & $\%$ & \\
\hline \multicolumn{6}{|l|}{ Age (years) } \\
\hline$<65$ years & 12 & $70.6 \%$ & 3 & $100 \%$ & \multirow[t]{2}{*}{$0.539(\mathrm{NS})$} \\
\hline$\geq 65$ years & 5 & $29.4 \%$ & 0 & $0 \%$ & \\
\hline \multicolumn{6}{|l|}{ KPS (\%) } \\
\hline$<70 \%$ & 2 & $11.8 \%$ & 0 & $0 \%$ & \multirow[t]{2}{*}{$0.551(\mathrm{NS})$} \\
\hline$\geq 70 \%$ & 15 & $88.2 \%$ & 3 & $100 \%$ & \\
\hline \multicolumn{6}{|l|}{ Number of metastasis } \\
\hline$\leq 4$ & 13 & $76.5 \%$ & 2 & $66.7 \%$ & \multirow[t]{2}{*}{$0.601(\mathrm{NS})$} \\
\hline$>4$ & 4 & $00 \%$ & 1 & $33.3 \%$ & \\
\hline \multicolumn{6}{|l|}{ Prior chemotherapy } \\
\hline Absent & 4 & $23.5 \%$ & 0 & $0 \%$ & \multirow[t]{2}{*}{$0.348(\mathrm{NS})$} \\
\hline Present & 13 & $76.5 \%$ & 3 & $100 \%$ & \\
\hline \multicolumn{6}{|l|}{ Extra cranial metastasis } \\
\hline Absent & 6 & $35.3 \%$ & 1 & $33.3 \%$ & \multirow[t]{2}{*}{$0.948(\mathrm{NS})$} \\
\hline Present & 11 & $64.7 \%$ & 2 & $66.7 \%$ & \\
\hline \multicolumn{6}{|l|}{ Response to treatment } \\
\hline Response & 8 & $47.1 \%$ & 1 & $33.3 \%$ & \multirow[t]{2}{*}{$0.579(\mathrm{NS})$} \\
\hline NO response & 9 & $52.9 \%$ & 2 & $66.6 \%$ & \\
\hline
\end{tabular}

Table 5:- Treatment toxicity.

\begin{tabular}{|c|c|c|c|}
\hline Hematological Toxicity (Grade I-III) & $\begin{array}{c}\text { (WBI }) \mathrm{A} \\
(20)\end{array}$ & $\begin{array}{c}\text { (WBI+TMZ) B } \\
(20)\end{array}$ & p-value \\
\hline Thrombocytopenia & $2(10 \%)$ & $4(20 \%)$ & $0.677(\mathrm{NS})$ \\
\hline Leucopenia & $6(30 \%)$ & $10(50 \%)$ & $0.333(\mathrm{NS})$ \\
\hline Anemia & $4(20 \%)$ & $5(25 \%)$ & $0.500(\mathrm{NS})$ \\
\hline Non hematological toxicity: & & & \\
\hline Vomiting & $6(30 \%)$ & $80(40 \%)$ & $0.741(\mathrm{NS})$ \\
\hline Headache & $15(75 \%)$ & $11(55 \%)$ & $0.185(\mathrm{NS})$ \\
\hline Alopecia & $8(40 \%)$ & $4(20 \%)$ & $0.168 \mathrm{NS}$ \\
\hline Scalp redness & $8(40 \%)$ & $4(20 \%)$ & $0.186 \mathrm{NS}$ \\
\hline
\end{tabular}




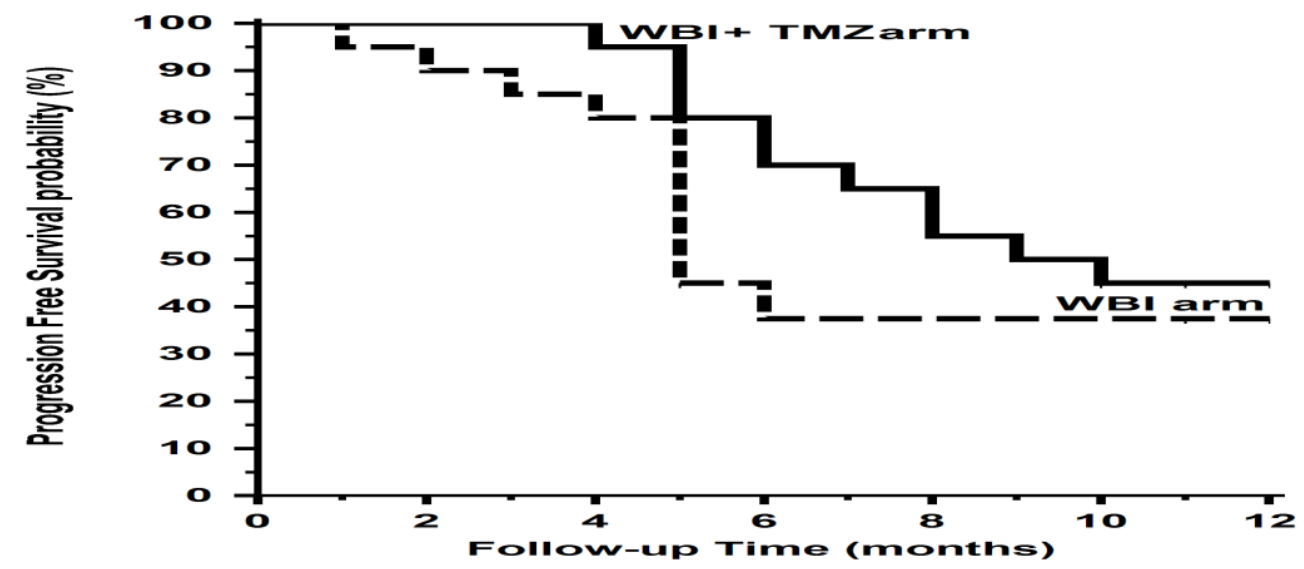

Figure 1:- Brain metastasis progression free survival in both treatment groups.

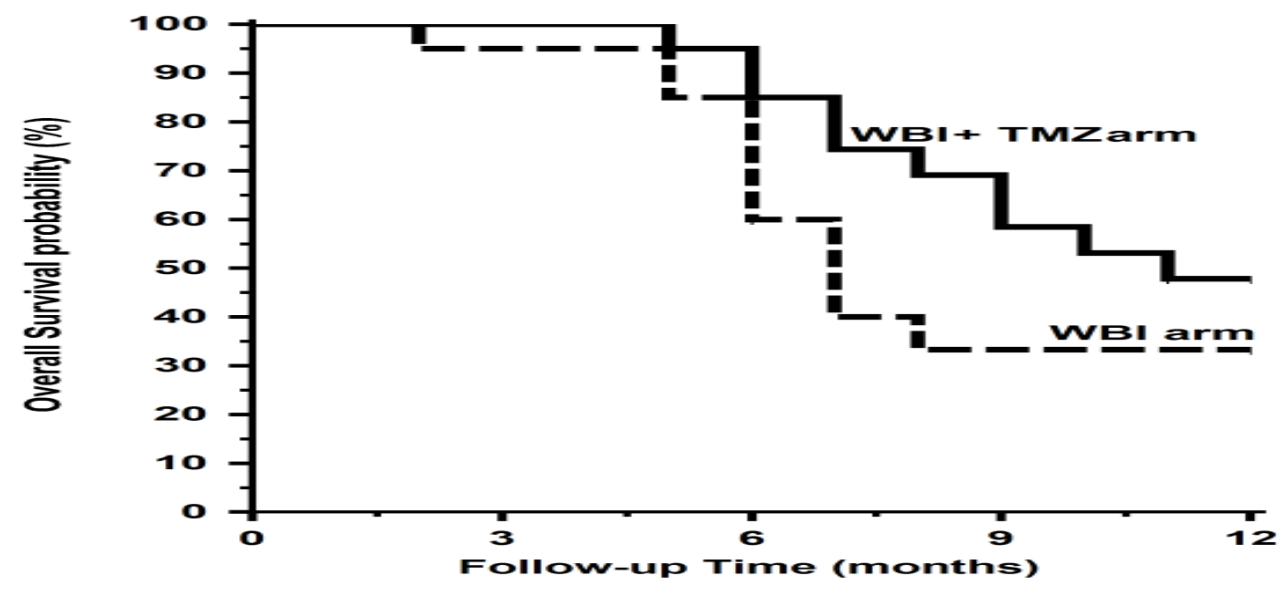

Figure 2:- Overall survival in both treatment groups.

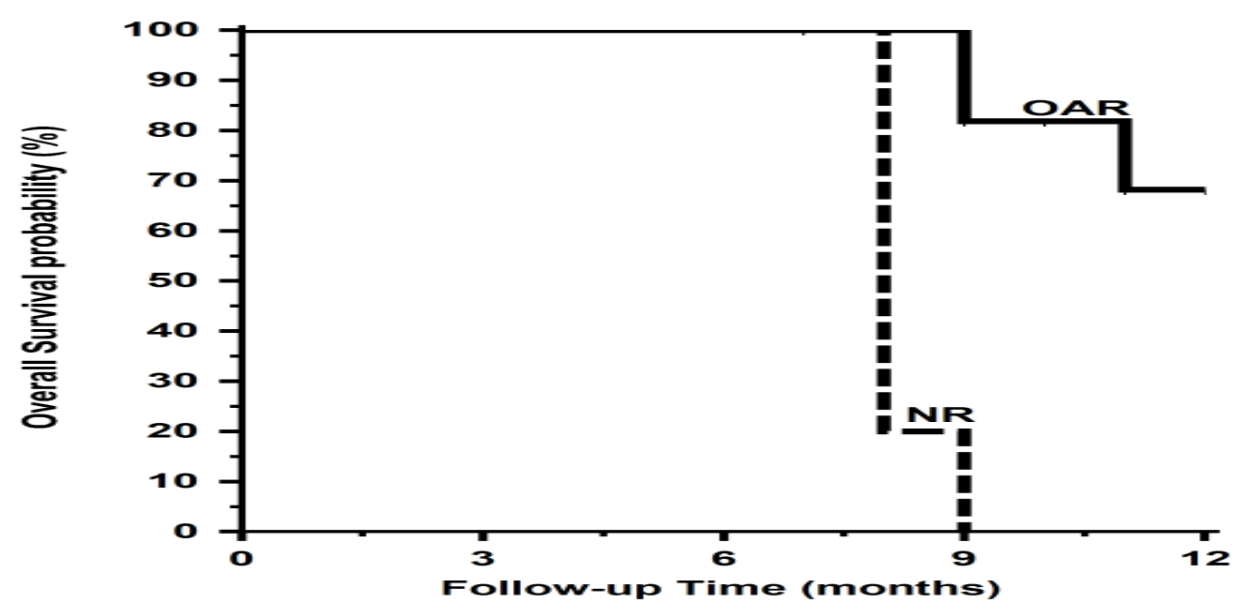

Figure 3:- Kaplan Meier plot of overall survival of WBI+TMZ arm stratified by response o treatment. 


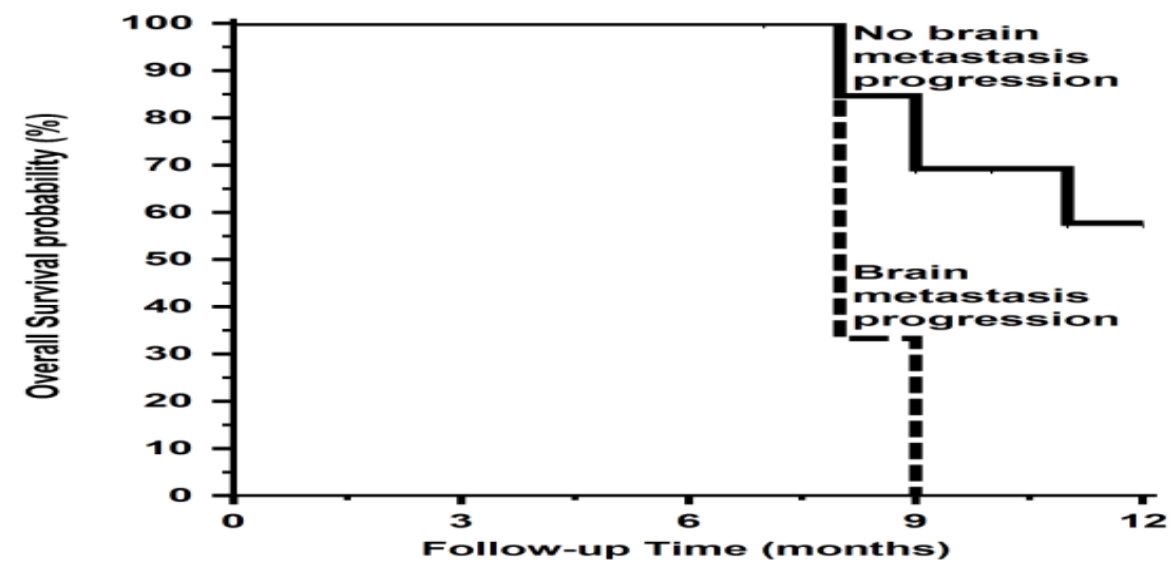

Figure 4:-Kaplan Meier plot of overall survival of WBI+TMZ arm stratifiedpresence of brain metastasis progression.

\section{Discussion:-}

The incidence of brain metastases increased over the past years. Treatment choices are limited. Whole-brain radiotherapy is considered the standard of care in patients with multiple or inoperable brain metastasesbut with limited value and with median overall survival less than six months. Several interesting studies have reported response rates using WBRT plus concomitant temozolomide(8). The outcomes of TMZ plus WBI arm may bedue to DNA damage effect of TMZ. Also,tumor cells expressing the enzyme methyl guanine methyl transferase (MGMT)could overcome the resistance to TMZ by high daily dose of TMZ with WBI (22)

This study was carried out in an attempt to evaluate the efficiency and safety of the concomitant temozolamide and whole brain radiotherapy in cases of brain metastases in breast cancer patients. The objective response rate (ORR) in WBRT+TMZ arm was $45 \%$ versus $40 \%$ in WBRT arm $(\mathrm{p}=0.749)$.

Although the same patient population were included ;patients with newly diagnosed intra parenchymal brain metastases from breast cancer; our results differ from that of Cao et al. study where patients were treated with conformal brain irradiation (300 cGy in ten fractions to $30 \mathrm{~Gy}$ ), with or without concurrent TMZ taken at a dosage of $75 \mathrm{mg} / \mathrm{m} 2 /$ day. After six weeks of treatment,objective response rates were $36 \%$ in the WBI group and $30 \%$ in the WBI + TMZ group.

The objective response rate in our study is lower than that of Antonadou et al. study that included patients with brain metastasis from both lung and breast cancer ;their ORR was 96\% in WBRT+TMZ group versus 67\% in WBIgroup ( $\mathrm{p}=0.017)$. WBI was gave as 40 Gy over 4 weeks, TMZ $75 \mathrm{mg} / \mathrm{m} 2$ per day, days $1-28$; subsequent TMZ $200 \mathrm{mg} / \mathrm{m} 2$ per day, days 1-5/28-d cycle for six cycles but these results were not confirmed with brain metastases from lung cancer in phase III study conducted by the same authors $(14,15)$.

Another study by Gamboa et al.(9)evaluated the management of patients with brain metastases from solid tumors by use of dose dense regimen of TMZ concomitant with $30 \mathrm{~Gy}$ whole brain radiation therapy over two weeks with no adjuvant TMZ versus only WBI.The objective response (OR) was 78.6\% for the concomitant arm( TMZ+WBI).

The present study gave the same ORR (45\%) as Addeo et al study in which patients received concurrent WBRT(30 Gy) with TMZ (75 mg/m2/day) over 10 days, then TMZ (150 mg/m2/day) for six cycles(7).

Verger et al study evaluate WBRT (30 Gy ) alone or combined with TMZ ( $75 \mathrm{mg} / \mathrm{m} 2 / \mathrm{d})$ followed by two cycles of TMZ (200 mg/m2/d for 5 days every 28 days). The radiologic response was evaluated on day30.Theresponse rate in WBRT+TMZ was 37\%, the difference in radiologic response between the two groups was statistically not significant (12).

In a meta-analysisfrom seven studies, Qian Zhao et al. reported that RT concomitant with TMZ could improve ORR compared with RT alone(10).

In our study, Median progression-free survival ( PFS) was six months in group A and9.5 in group B arm with non 
significant difference. Median overall survival was seven months in group A versus 11 months in group B with nonsignificant difference $(\mathrm{p}=0.143)$.

These results are lower than that of Addeo et al. in where median PFS was nine months and median overall survival was 13 months ,but there was a significant difference in PFS in both arms. Gamboa-vignolle et al. study, median PFS was 11.8 months for WBRT+TMZ arm versus 5.6 months in WBRT arm $(\mathrm{p}=0.005)$ and median overall survival were eight months and 8.1 months (not significant) for aWBRT+TMZ arm and WBRT arm ,respectively.This confirmed that the combined treatment of RT with TMZ might delay the progression of BM with no impact on overall survival(7\&9). Qian Zhao et al. (10)reported that no significant difference in PFS or OS between the two treatment arms .

In our study all patients were evaluated regard treatment tolerability;the two treatment arms showed no significant difference. Treatment toxicity in the TMZ +WBRT arm was well tolerated, with frequently grade 1 or 2 toxicity. Hematological toxicity constituted the most common event of adverse effects in this arm.

Leukopenia was observed in $41 \%$ of patients ,Anemia was observed in $38 \%$ of patients and thrombocytopenia was seen in $24 \%$ of patients. However this effect were found to resolve easily and resulted in only minor treatment delays. While in Qian Zhao et al meta analysis (10), the TMZ plus RT arm had produced significantly more grade 3 to 4 nausea and thrombocytopenia

According to these results, the treatment regimen which used in this study showed some benefits over the dosedense TMZ regimens.In addition, this treatment did not lead to the toxic effects associated with delayed TMZ schedules which occur in up to $91 \%$ of patients receiving up to 10 cycles of protracted low-dose TMZ (13).

Several studies were for TMZ plus RT with median overall survival of 12 months and a satisfactory level for the quality of life $(7,16-18)$. However, individually, only one out of 7 randomized controlled trials RCTs included in this meta-analysis showed a some survival improvement following the addition of temozolomide to radiotherapy, with median survival times of 7and 8.6 months in the RT arm and TMZ plus RT arm, respectively (15). In four randomized controlled trials that compare radiotherapy to concomitant TMZ and RT, the OS was lower in patients who were treated with combination TMZ and RT(11,19-21)

It is hard to compare the results of our study, that was performed on a homogenous group of patients ;with the previously mentioned studies which included more heterogeneous groups of patients and with different treatment regimens.

\section{Conclusion:-}

Although the concomitant WBI and TMZ was safe and may improve local control, OS and PFS of BMs from breast cancer in this study,this improvement was non- significant, and to recommend this line of treatment; another more studies with larger number of patients are needed to get significant results.

\section{Reference:-}

1. Langer CJ, Mehta MP. Current management of brain metastases, with a focus on systemic options.JClinOncol. 2005;23:6207-19. doi: 10.1200/JCO.2005.03.145. PMID:16135488.

2. Pestalozzi, B.C.(2009), Brain metastases and subtypes of breast cancer. Ann Oncol, 2009. 20(5): p. 803-5.

3. Cappuzzo F, Mazzoni F, Maestri, Di Stefano A, Calandri C, Crino L: Medical treatment of brain metastases from solid tumours Forum Genova) 2000, 10:137-149.

4. Scoccianti S, Ricardi U. Treatment of brain metastases: review of phase III randomized controlled trials. RadiotherOncol. 2012;102:168-79. doi: 10.1016/j.radonc.2011.08.041. PMID:21996522

5. John H. Suh, MD, Samuel T. Chao, MD, and Michael A. Vogelbaum, MD, PhD.(2009). (Management of brain metastases 2009) Current Neurology and Neuroscience Reports(Journal), , 9:223-230 Current Medicine Group LLC ISSN 1528-4042 Copyright @ 2009

6. vanVulpen M, Kal HB, Taphoorn MJ, El-SharouniSY.Changes in blood-brain barrier permeability induced byradiotherapy: implications for timing of chemotherapy? (Review).Oncol Rep 2002; 9: 683-688 [PMID: 12066192 
7. Addeo R, Caraglia M, Faiola V, Capasso E, et al. Concomitant treatment of brain metastasis with whole brain radiotherapy [WBRT] and temozolomide [TMZ] is active and improves quality of life. BMC Cancer. 2007;7: 18. doi: 10.1186/1471-2407-7-18. PMID:17254350

8. Christodoulou C, Bafaloukos D, Linardou H, AravantinosG. Temozolomide(TMZ) combined with cisplatin (CDDP) in patients with brain metastases from solid tumors: a Hellenic Cooperative Oncology Group (HeCOG) Phase II study. J Neurooncol 2005;71: 61-65 [PMID: 15719277 DOI: 10.1007/s11060-004-9176-0]

9. Gamboa-Vignolle C, Ferrari-Carballo T, Arrieta Ó, Mohar A. Whole-brain irradiation with concomitant daily fixed-dose Temozolomide for brain metastases treatment: A randomised phase II trial. RadiotheryOncol. 2012;102:187-191. doi: 10.1016/j.radonc.2011.12.004. PMID:22257825

10. Zhao Q, Qin Q, Sun J, Han D, Wang Z, Teng J, et al. (2016) Brain Radiotherapy plus Concurrent Temozolomide versus Radiotherapy Alone for Patients with Brain Metastases: A Meta-Analysis. PLoS ONE 11(3): e0150419. doi:10.1371/journal.pone.0150419

11. Cao KI, Lebas N, Gerber S, Levy C, Le Scodan R, BourgierC,et al. Phase II randomized Study of Whole Brain Radiation Therapy with or without concurrent temozolomide for Brain Metastases from breast cancer. Ann Oncol. 2015;26:89-94. doi: 10.1093/annonc/mdu488. PMID:25355723

12. Verger E, Gil M, Yaya R, Viñolas N, Villà S, Pujol T, et al. Temozolomide and concomitant Whole Brain radiotherapy in patients with Brain Metastases a Phase II randomized trial. Int J RadiatOncolBiol Phys. 2005;61:185-191. PMID:15629610doi: 10.1016/j.ijrobp.2004.04.061

13. TosoniA, Cavallo G, Ermani M, et al. Is protracted low-dose temozolomidefeasible in glioma patients? Neurology 2006;66:427-9.

14. AntonadouD,Coliarakis N, Paraskevaidis $\mathrm{M}$, Athanasiou H, e tal. A multi-institutional trial comparing survival of patients with brain metastases fromlung cancer treated with temozolomide plus radiotherapy versus to radiotherapy alone. LungCancer. 2003;41:S22-3.

15. Antonadou D, Paraskevaidis M, Sarris G, ColiarakisN,Economou I, Karageorgis P, Throuvalas N. Phase II randomizedtrial of temozolomide and concurrent radiotherapyin patients with brain metastases. J ClinOncol 2002; 20:3644-3650 [PMID: 12202665]

16. Qin H, Pan F, Li J, Zhang X, Liang H, Ruan Z. Whole Brain Radio therapy Plus Concurrent Chemotherapy in Non-Small Cell Lung Cancer Patients with Brain Metastases: A Meta-Analys. PLoS One. 2014;9:e111475. doi: 10.1371/journal.pone.0111475. PMID:25347291

17. Dziadziuszko R, Ardizzoni A, Postmus PE, Smit EF, Price A, Debruyne C, et al. Temozolomide in patients with advanced non-small cell lung cancer with and without brain metastases: a phase II study of the EORTC Lung Cancer Group (08965). Eur J Cancer. 2003;39:1271-1276. PMID:12763216doi: 10.1016/s09598049(03)00234-x

18. Pesce GA, Klingbiel D, Ribi K, Zouhair A, von Moos R, Schlaeppi M, et al. Outcome, quality of life and cognitive function of patients with brain metastases from non-small cell lung cancer treated with whole brain radiotherapy combined with gefitinib or temozolomide. A randomised phase II trial of the Swiss Group for Clinical Cancer Research (SAKK 70/03).Eur J Cancer. 2012;48:377-384. doi: 10.1016/j.ejca.2011.10.016. PMID:22093943

19. Chua D, Krzakowski M, Chouaid C, Pallotta MG, Martinez JI, Gottfried M, et al. Whole-Brain Radiation Therapy Plus Concomitant Temozolomide for the Treatment of Brain Metastases From Non-Small-Cell Lung Cancer: A Randomized, Open Label Phase II Study. Clin Lung Cancer. 2010;11:176-181. doi: 10.3816/CLC.2010.n.022. PMID:20439193

20. Hassler MR, Pfeifer W, Knocke-Abulesz TH, Geissler K, Altorjai G, Dieckmann K, et al. Temozolomide added to whole brain radiotherapy in patients with multiple brain metastases of non-smallcell lung cancer: a multicentric Austrian phase II study. Wien KlinWochenschr. 2013;125:481-486. doi: 10.1007/s00508-0130402-7. PMID:23907204

21. Sperduto PW, Wang M, Robins HI, Schell MC, Werner-Wasik M, Komaki R, et al. A Phase 3 Trial of Whole Brain Radiation Therapy and Stereotactic Radiosurgery Alone Versus WBRT and SRS WithTemozolomide or Erlotinib for Non-Small Cell Lung Cancer and 1 to 3 Brain Metastases: Radiation Therapy Oncology Group 0320. Int J RadiatOncolBiol Phys. 2013;85:1312-1318. doi: 10.1016/j.ijrobp.2012.11.042. PMID:23391814

22. Brett L. Carlson, B.S.,1 Patrick T. Grogan,1 Ann C. Mladek, B.S, et al. Radiosensitizing effects of TMZ observed in vivo only in a subset of MGMT methylated GBM xenograftsInt J RadiatOncolBiol Phys. 2009 Sep 1; 75(1): 212-219. 